\title{
Nachhaltige Verpackungsklebstoffe
}

Die Jowat-Schmelzklebstoffe der Produktreihe GROW verfügen über einen hohen Anteil nachwachsender Rohstoffe und ermöglichen im Verarbeitungsprozess eine hohe Effizienz und Sauberkeit sowie recyclingfähige Klebungen im Sinne des deutschen Verpackungsgesetzes.

\section{Reduzierung von Stillstandzeiten}

Highlight dieser Produktfamilie für nachhaltiges Verpacken ist der Klebstoff mit der Bezeichnung GROW 853.20, der nach Angaben von Jowat neben seinem biobasierten Rohstoffanteil auch besonders ressourcenschonend sei, da er bereits bei Temperaturen ab $120^{\circ} \mathrm{C}$ verarbeitet werden könne. Das Ergebnis sei ein sparsamer und effizienter Energieeinsatz bei gleichzeitiger Optimierung der Arbeitsumgebung. Der Klebstoff überzeuge zudem in Sachen Sauberkeit: Aufgrund seines besonders scharfen Fadenabrisses werde sowohl einer Materialverschwendung als auch der Verschmutzung von Anlageteilen und Verpackungen vorgebeugt. Jowat betont, dass dank der sehr hohen thermischen Stabilität des Hotmelts Wartungsaufwand und Stillstandzeiten erheblich reduziert und die Lebensdauer der Betriebsmittel verlängert werden. Mit den nachhaltigen Klebstofflösungen der Produktlinie GROW bietet Jowat nach eigenen Angaben leistungsstarke biobasierte Hotmelts für zahlreiche Anwendungen in Verpackungsprozessen. Ihr breites Adhäsionsspektrum ermögliche eine sichere Klebung auch auf anspruchsvollen Oberflächen. Wegen ihrer hohen Kälteflexibilität seien sie auch für Tiefkühlanwendungen geeignet. // Weitere Informationen: www.jowat.com

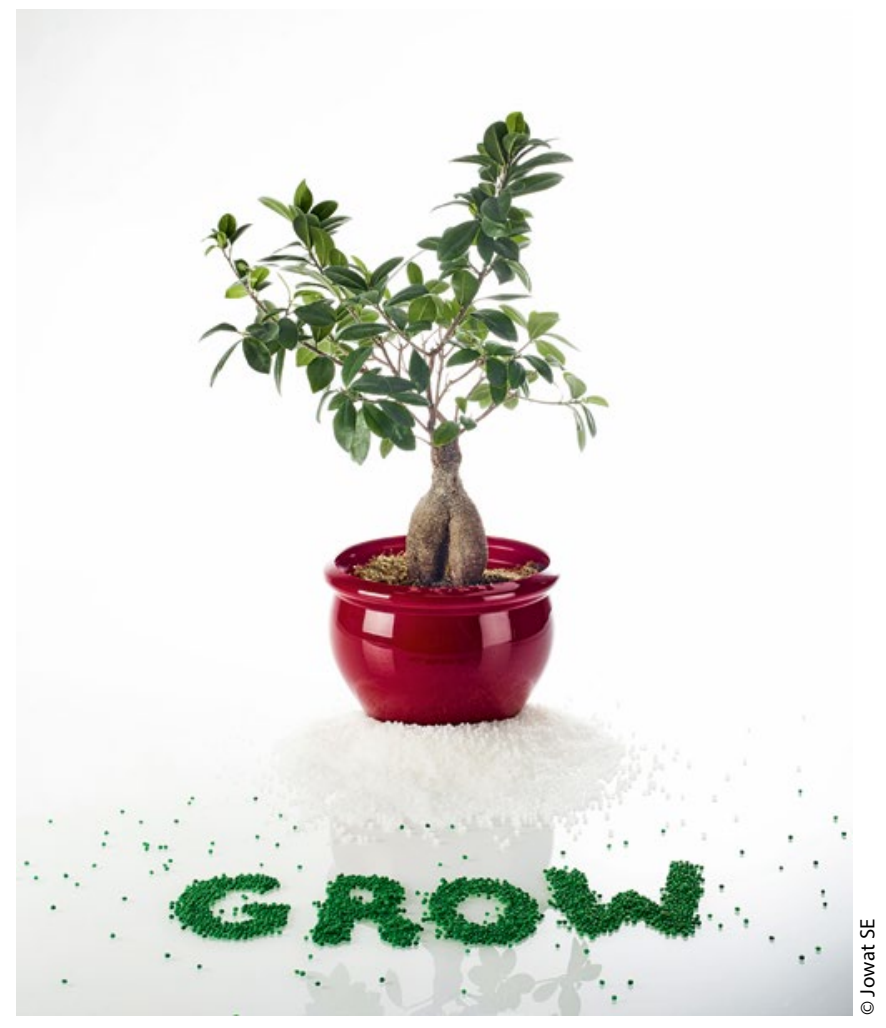

Die Klebstoffe der Produktreihe GROW von Jowat verfügen über einen hohen Anteil nachwachsender Rohstoffe.

\section{Neuer wärmeleitfähiger Klebstoff für hitzeempfindliche Bauteile}

Panacol hat einen neuen wärmeleitfähigen Klebstoff entwickelt, der bereits schon bei Temperaturen $\mathrm{ab} 80^{\circ} \mathrm{C}$ im Ofen ausgehärtet werden kann. Er zeichne sich laut Her-

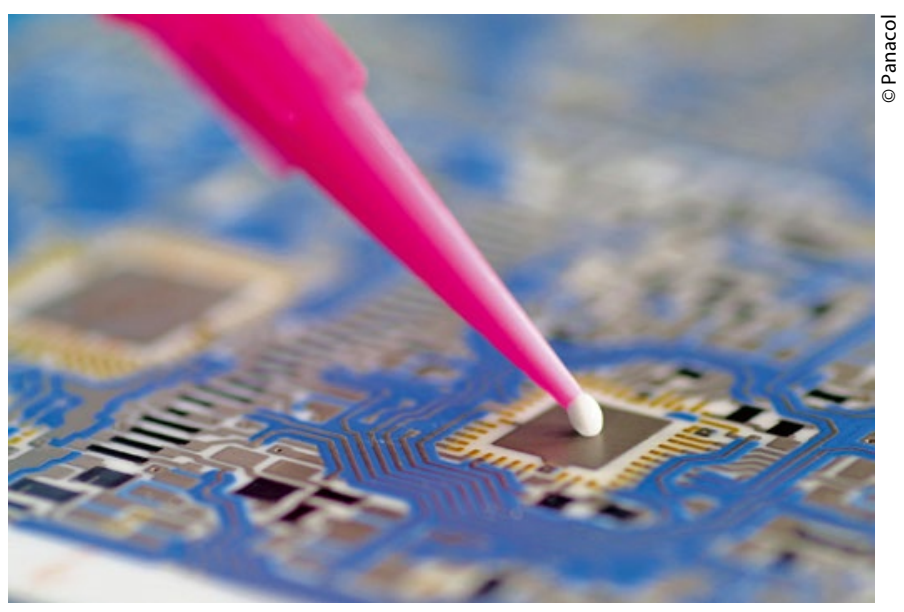

Der Klebstoff Elecolit 6607 eignet sich insbesondere zum Verkleben von Komponenten auf elektronischen Leiterplatten. der Bezeichnung Elecolit 6607 ist mit Aluminiumoxid gefüllt und soll aufgrund seiner Fließeigenschaften mittels Dispenser, Siebdruck oder Spachtel verarbeitet werden können.

Der Klebstoff lasse sich nach Angabe von Panacol schon bei Temperaturen ab $80^{\circ} \mathrm{C}$ aushärtet und könne auch hitzeempfindliche Bauteile miteinander verbinden. Durch höhere Aushärtetemperaturen werde die Aushärtezeit verkürzt.

Panacol betont, dass der hellgraue Klebstoff nach der Aushärtung gleichzeitig elektrisch isolierend und wärmeableitend sei. Aufgrund seiner Eigenschaften eigne sich Elecolit 6607 insbesondere zum Verkleben von Metallbauteilen und Kühlkörpern auf elektronischen Leiterplatten. //

Weitere Informationen: www.panacol.de 